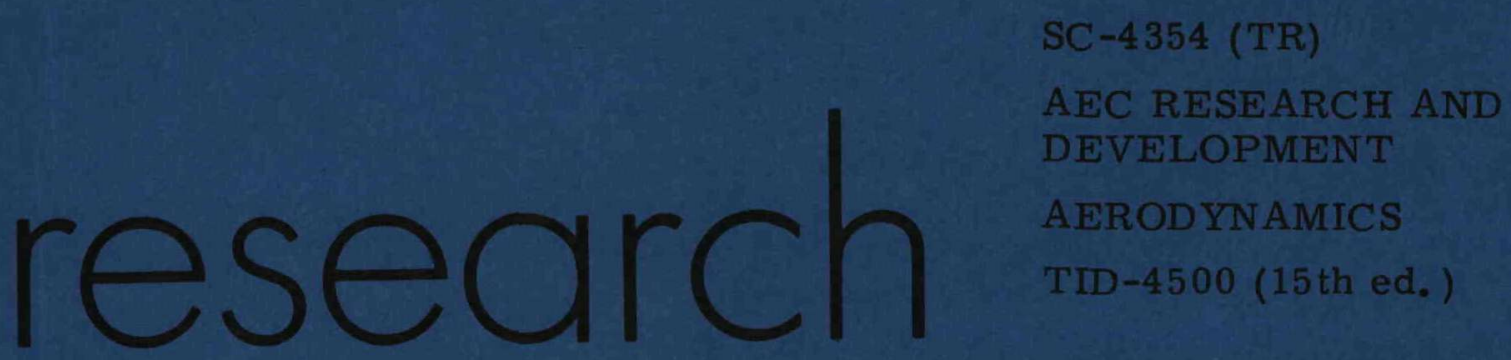

report

EXPERIMENTAL DETERMINATION

OF THE

PRESSURE DROP THROUGH A PEBBLE BED

D. E. Randall, 5142

S. S, Millwright, 5142

September 1959
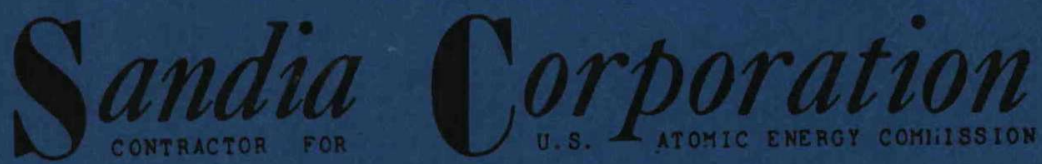


\section{EXPERIMENTAL DETERMINATION \\ OF THE \\ PRESSURE DROP THROUGH A PEBBLE BED}

D. E. Randall, 5142

S. S. Millwright, 5142

September 1959

\section{ABSTRACT}

The pressure drop associated with the flow of air through a cylindrical bed of spherical pebbles has been investigated experimentally. The results of this investigation are reported here, 


\section{DISCLAIMER}

This report was prepared as an account of work sponsored by an agency of the United States Government. Neither the United States Government nor any agency Thereof, nor any of their employees, makes any warranty, express or implied, or assumes any legal liability or responsibility for the accuracy, completeness, or usefulness of any information, apparatus, product, or process disclosed, or represents that its use would not infringe privately owned rights. Reference herein to any specific commercial product, process, or service by trade name, trademark, manufacturer, or otherwise does not necessarily constitute or imply its endorsement, recommendation, or favoring by the United States Government or any agency thereof. The views and opinions of authors expressed herein do not necessarily state or reflect those of the United States Government or any agency thereof. 


\section{DISCLAIMER}

Portions of this document may be illegible in electronic image products. Images are produced from the best available original document. 


\section{TABLE OF CONTENTS}

$\underline{\text { Page }}$

ABSTRACT

LIST OF SYMBOLS

SUMMARY

4

Introduction

Apparatus and Test Procedure

Results and Discussion

Porosity

Steady-State Pressure Drop

Transient Pressure Drop

9

10

12

Conclusions and Recommendations

\section{LIST OF ILLUSTRATIONS}

Figure

Page

$\begin{array}{ll}\text { 1. Schematic Diagram of Test Setup } & 7\end{array}$

2. Photograph of Pebble Bed and Test Setup $\quad 8$

3. Porosity of Cylindrical Pebble Bed versus Bed-to-Pebble-Diameter Ratio 9

4. Air-Flow Rate for the 1-Inch-Diameter Flat Plate Orifice 10

5. Pressure Drop versus Flow Rate for the Pebble Bed 11

6. Pressure-Drop Parameter versus Reynolds Number for the Pebble Bed 14

7. Reproductions of Selected Frames of Motion-Picture Film of Pebbles in Motion 


\section{LIST OF SYMBOLS}

A Total cross-sectional area of bed, $\mathrm{ft}^{2}$

a Flow area at any bed cross section $=\mathrm{Ae}, \mathrm{ft}^{2}$

C Orifice discharge coefficient, dimensionless

$D$ Orifice diameter, inches

$D_{1}$ Pebble bed diameter, feet

d Diameter of pebbles, feet

$\frac{\mathrm{dP}}{\mathrm{dx}}$ Pressure drop per unit length of pebble bed, $1 \mathrm{~b} / \mathrm{ft}^{3}$

e Porosity of pebble bed, ratio of void volume to total volume of pebble bed, dimensionless

$\mathrm{g}$ Acceleration of gravity, ft/ $/ \mathrm{sec}^{2}$

$h_{w}$ Pressure differential across orifice, inches $\mathrm{H}_{2} \mathrm{O}$

$P_{0}$ Pressure upstream of orifice, psia

$\Delta \mathrm{P}_{\mathrm{o}}$ Pressure differential across orifice, psi

$\Delta P / L$ Pressure drop per unit length of pebble bed, $1 \mathrm{~b} / \mathrm{ft}^{3}$

$R_{e}$ Reynolds number based on fluid properties at bed and pebble surface area per unit volume, $R_{e}=\rho_{1} u / \mu S$

$S$ Area of pebble surface per unit volume of packed bed, $1 / \mathrm{ft}$

$S_{1}$ Total surface area per unit volume inclusive of wall surface, $1 / \mathrm{ft}$

$u$ Apparent fluid velocity based on empty container, $\mathrm{ft} / \mathrm{sec}$

$\mathrm{V}$ Apparent fluid velocity based on flow area in bed, $\mathrm{ft} / \mathrm{sec}$

w Air flow rate through orifice and bed, $1 \mathrm{~b} / \mathrm{sec}$

$\mathrm{Y}_{1}$ Factor to account for fluid expansion, dimensionless

$\beta$ Ratio of orifice diameter to pipe diameter, dimensionless.

$\rho_{\mathrm{b}}$ Bulk density of pebble bed, $(1-\mathrm{e}) \rho_{\mathrm{m}}, \mathrm{lb} / \mathrm{ft}^{3}$

$\rho_{\mathrm{m}}$ Density of pebble material, $\mathrm{lb} / \mathrm{ft}^{3}$

$\rho_{\mathrm{o}}$ Fluid density at orifice, $\mathrm{lb} / \mathrm{ft}^{3}$

$\rho_{1}$ Fluid density in bed, $1 \mathrm{~b} / \mathrm{ft}^{3}$

$\mu$ Fluid viscosity in bed, $\mathrm{lb} / \mathrm{ft} \mathrm{sec}$ 


\section{SUMMARY}

In designing a wind-tunnel air heater, it became necessary to determine under what conditions a cylindrical bed of spherical pebbles, restrained by gravity only, would be lifted by the flow of a gas upward through the bed. This report presents the results of a test conducted to determine the allowable pressure drop across such a pebble bed.

Under steady flow conditions, the pebbles started lifting when the pressure drop per unit length of bed attained a value equal to 85 percent of the bed bulk density. Under simulated tunnel starting conditions, the pebbles did not start lifting until the peak value of transient pressure drop per unit length attained 85 percent of the bed bulk density. 
EXPERIMENTAL DETERMINATION OF THE

PRESSURE DROP THROUGH A PEBBLE BED

\author{
Introduction
}

High stagnation temperatures are required to avoid liquefaction of the air in the test section of a hypersonic wind tunnel. An economical method (energywise) of providing high temperatures for an intermittent tunnel is to pass the high-pressure storage air through a vertical bed of heated alumina pebbles. This heating method is being incorporated in the design of a $4 \leq \mathrm{M} \leq 9,2500^{\circ} \mathrm{F}, 18$-inch-diameter test-section intermittent wind tunnel at Sandia Corporation.

The $2500^{\circ} \mathrm{F}$ air temperature makes it impractical to support or restrain the pebbles mechanically at the heater outlet. Hence, the heater is designed to pass the air upward through the pebble bed, with the pebbles restrained only by gravity.

The pebble bed must be sized to pass the flow rate required by the tunnel while keeping air velocity in the bed low enough that the pressure drop will not cause the pebbles to lift. Initial investigation of this problem disclosed a wide variation of opinion as to what pressure drop could be allowed without lifting pebbles. Bloom ${ }^{1}$ states that the allowable pressure drop per foot is equal to pebble material density (250 lbs/ $\mathrm{ft}^{3}$ for alumina pebbles) and designs to a value of $163 \mathrm{lbs} / \mathrm{ft}^{3}$, giving a 'factor of safety' of 1.533 .

Discussions with a vendor on a proposed heater design disclosed a design criteria of allowable unit length pressure drop equal to 15 percent of bed bulk density. Bed bulk density is defined as pebble weight per unit volume of bed. This corresponds to a pressure drop for alumina pebbles of 18 to $25 \mathrm{lbs} / \mathrm{ft}^{3}$, depending on porosity. The Langley facility of the NASA designed a zirconia heater with an allowable pressure drop of 6 psi over a 20 -foot bed length. This corresponds to a unit length pressure drop of $43.2 \mathrm{lbs} / \mathrm{ft}^{3}$ for the denser zirconia pebbles.

The required pebble-bed diameter is inversely proportional to the fourth root of allowable pressure drop (see Equation 3, page 12). Thus, a 78-percent reduction in bed diameter is possible for a tenfold increase in allowable pressure drop. Such a reduction in bed diameter could lead to a reduction in insulation thickness and pressure vessel requirements, and such an increase in allowable pressure drop could lead to a significant reduction in over-all heater

${ }_{1}$ Bloom, Martin H., A High Temperature-Pressure Air Heater Suitable for Intermittent Hypersonic Wind-Tunnel Operation, WADC-TN-55-694, Nove mber 1956. 
size and cost. In view of the foregoing, a test was undertaken to determine what pressure drop would cause pebbles to lift.

\section{Apparatus and Test Procedure}

A test $r$ ig to simulate airflow through a cylindrical bed of cold spherical pebbles was set up in the equipment room of the wind tunnel building (Bldg. 865). The pebble bed consisted of a cylindrical shell of 7.5 -inch-inside-diameter lucite tubing, with a perforated plate in the bottom to support a column of pebbles approximately 15 inches deep. Glass marbles varying from 0.607 to 0.630 inch in diameter, with the mean diameter about 0.619 inch, were used for the pebbles in this test. Material density of the glass marbles is 157.6 pounds per cubic foot.

This bed was connected through appropriate piping and valving to the air storage supply for the transonic wind tunnel. This storage consists of 5200 cubic feet of air at $300-p s i$ maximum pressure. A 2-inch gate valve at the storage tank outlet served to isolate this entire system from the 300-psi air supply. A manual one-quarter-turn plug valve permitted quick opening or shutdown of this system. A 2-inch pressure-reducing valve dropped the line pressure from 300 psi upstream to approximately 3 psig downstream. A 2-inch globe valve provided manual control over the air-flow rate through the bed. Two-inch pipe was used from the storage tank through the globe valve. Downstream from the globe valve, the line was expanded from 2 to 4 inches.

A 1-inch-diameter flat-plate orifice was mounted in the 4-inch line to provide a measurement of the air-flow rate through the bed. A straight section of pipe, 10 diameters in length, was used upstream from the orifice, and a straight section approximately 20 diameters in length downstream. Figure 1 is a schematic diagram of this system. Figure 2 is a photograph of the test setup.

Instrumentation consisted of four CEC Type 4-312 differential pressure transducers. These transducers were connected through a stepping switch to a Brown "Electronik" strip chart recorder. The ranges for these four transducers, together with the parameter measured, are tabulated below:

\begin{tabular}{|c|c|c|}
\hline No. & Range, psi & Measurement \\
\hline 1 & 50 & Static pressure upstream of orifice \\
\hline 2 & 15 & Pressure differential across orifice \\
\hline 3 & 2.5 & Total pressure at bed inlet \\
\hline 4 & 2.5 & Pressure differential across bed \\
\hline
\end{tabular}

The test procedure followed was to increase the flow rate through the bed by small increments, at each step recording each of the above four parameters. Movement of the pebbles was observed visually. 


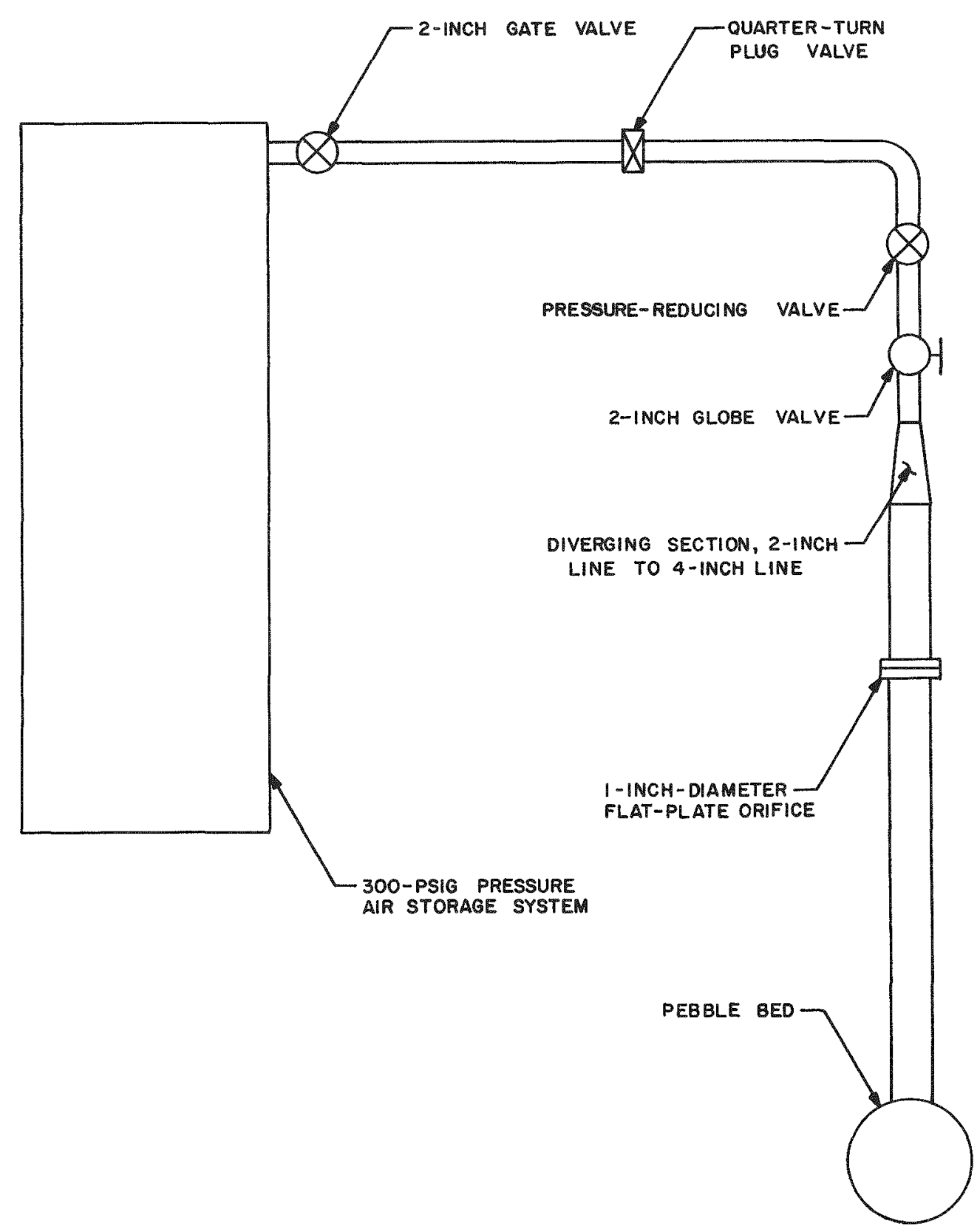

Figure 1. Schematic Diagram of Test Setup

An attempt was also made to determine the reaction of the pebble bed to the rapid pressure buildup experienced in starting a blowdown wind tunnel where the heater is not prepressurized. These conditions were simulated by presetting the globe valve to restrict the maximum flow rate. By opening the one-quarter-turn plug valve as rapidly as possible, 'starts' were made, recording total pressure at the bed inlet. These 'starts' were then repeated, recording pressure differential across the pebble bed. 


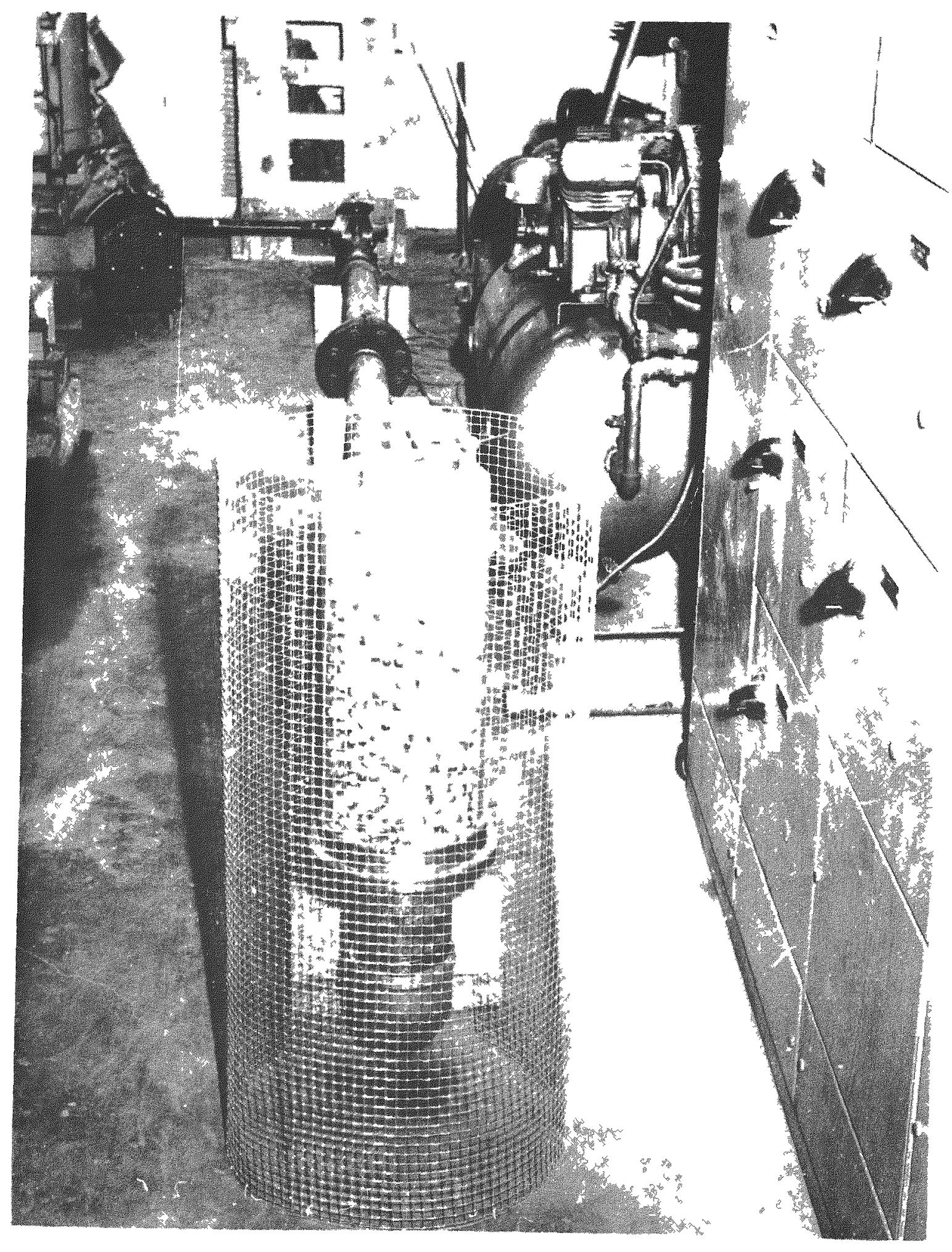

Figure 2. Photograph of Pebble Bed and Test Setup 


\section{Results and Discussion}

\section{Porosity}

The porosity of this pebble bed was found by measurement to be 39 percent. Bloom indicates that the porosity of packed beds of spheres is 48 to 50 percent, regardless of pebble size. This discrepancy led to a further investigation of the porosity of cylindrical pebble beds.

Porosity was measured at several values of bed-to-pebble-diameter ratio. In addition, porosities were calculated for diameter ratios $D_{1} / d<2$ from the equation:

$$
e=1-\frac{2}{3\left(\frac{D_{1}}{d}\right)^{2} \sqrt{\frac{D_{1}}{d}\left(2-\frac{D_{1}}{d}\right)}}
$$

These data, both calculated and experimental, agree well with porosity data presented by Carman. ${ }^{1}$ The results of this investigation, as well as Carman's data, are presented in Figure 3. This indicates that, at the diameter ratios usually associated with pebble heater design, the porosity varies from 35 to 40 percent. For the bed configuration used in this test (diameter ratio $=12.12$ ), the porosity was 39 percent, resulting in a bulk density for the pebble bed (weight of pebbles/cubic foot of bed) of 96.2 pounds per cubic foot.

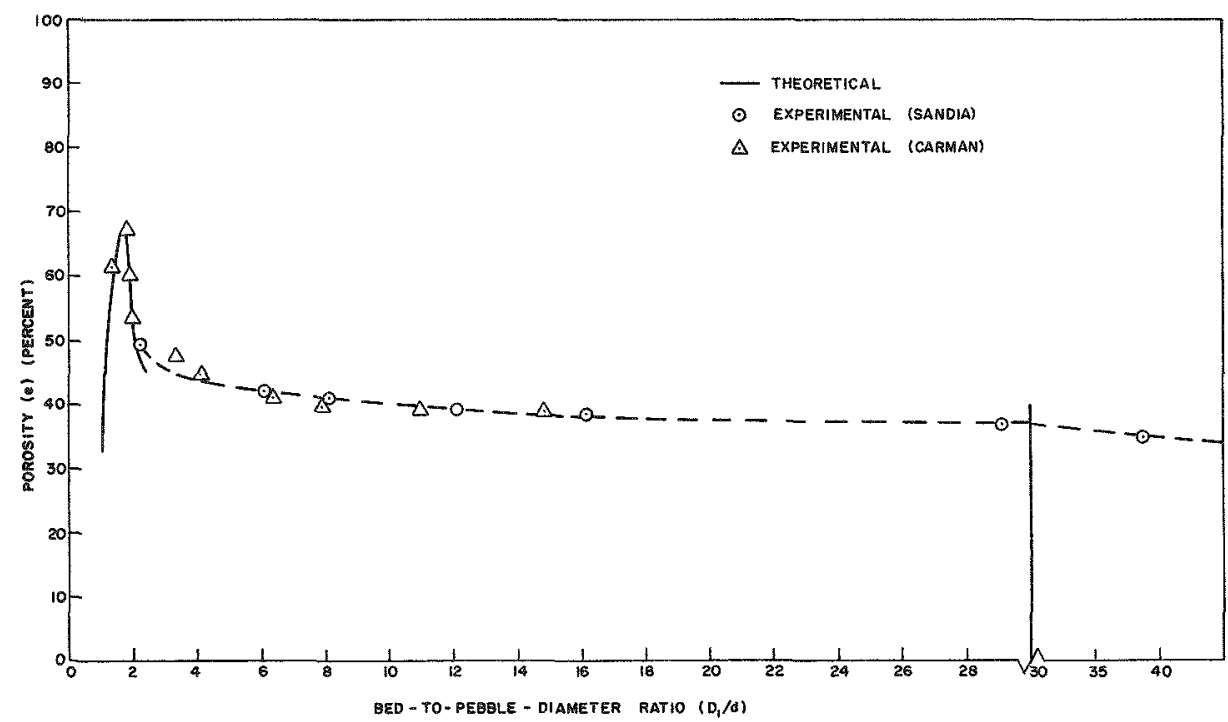

Figure 3. Porosity of Cylindrical Pebble Bed versus Bed-to-Pebble-Diameter Ratio

\footnotetext{
${ }^{1}$ Carman, P. C. "Fluid Flow Through Granular Beds," Transactions, Institution of Chemical Engineers, London, Vol. 15, 1937, p. 150.
} 
The air-flow rate through the pebble bed was calculated for each of the steady-state points from: ${ }^{1}$

$$
\mathrm{w}=0.0997 \frac{\mathrm{CD}_{\mathrm{o}}^{2}}{\sqrt{1-\beta^{4}}} \sqrt{\rho_{\mathrm{o}} \mathrm{w}_{\mathrm{w}}} \mathrm{Y}_{1}
$$

and has been plotted against $\sqrt{\Delta \mathrm{P}_{\mathrm{O}} / \mathrm{P}_{\mathrm{O}}}$ for the orifice in Figure 4.

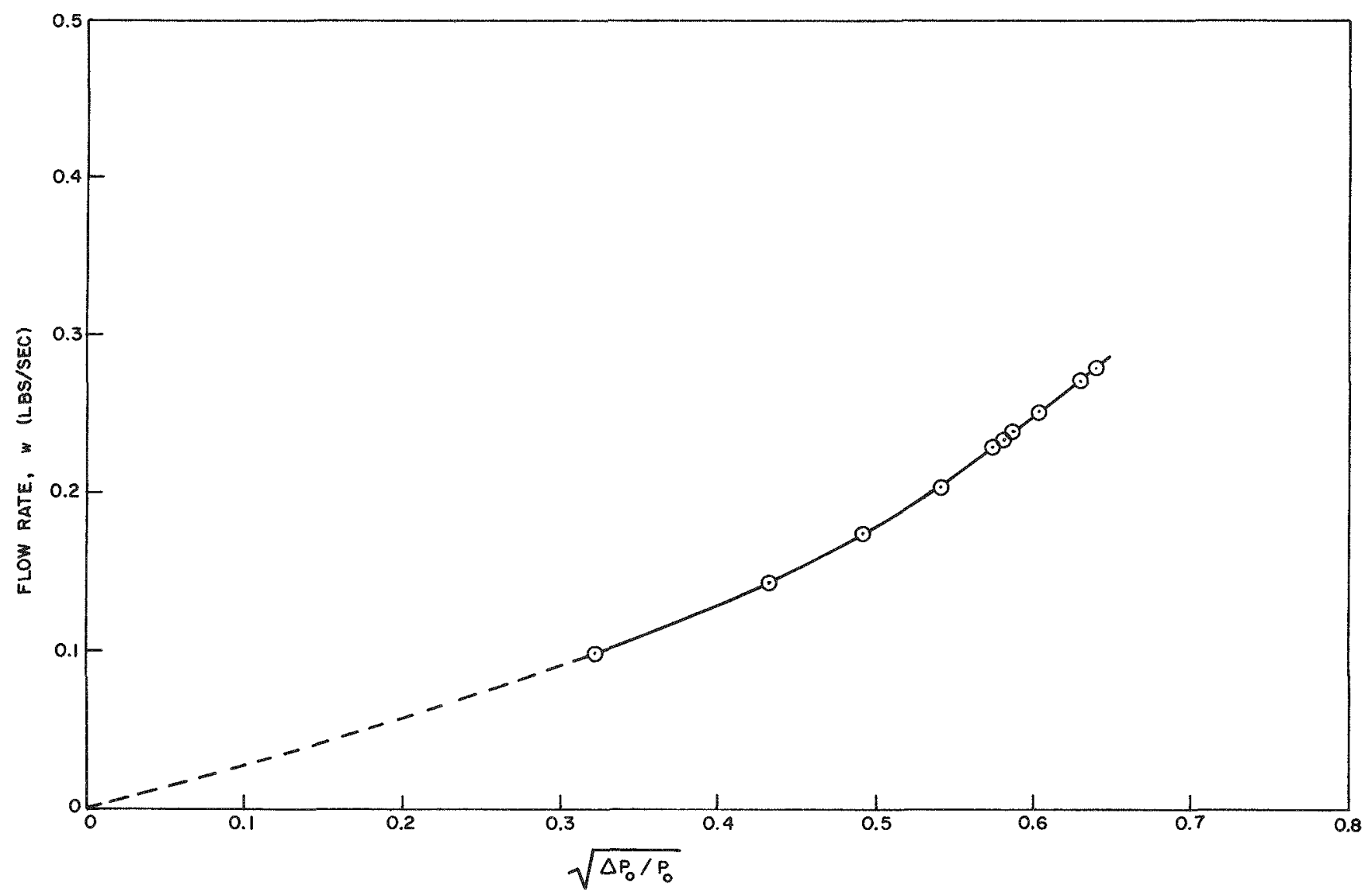

Figure 4. Air-Flow Rate for the 1-Inch-Diameter Flat Plate Orifice

${ }^{1}$ ASME Special Research Committee on Fluid Meters, Fluid Meters, Their Theory and Application, 4th ed., ASME, 1937. 
** The measured pressure drop across the pebble bed is plotted versus flow rate in Figure 5. Notations regarding pebble movement are made at appropriate data points. First indications of movement are a spinning motion of marbles in the top layer; further increase in flow results in a lifting of the top-layer marbles individually as well. Finally, a point is reached where a section of the bed lifts, and immediately the marbles on the bottom of this lifted column fall back. This continues until all the pebbles have fallen back, then the whole cycle is repeated, giving the appearance of a wave moving upward through the bed.

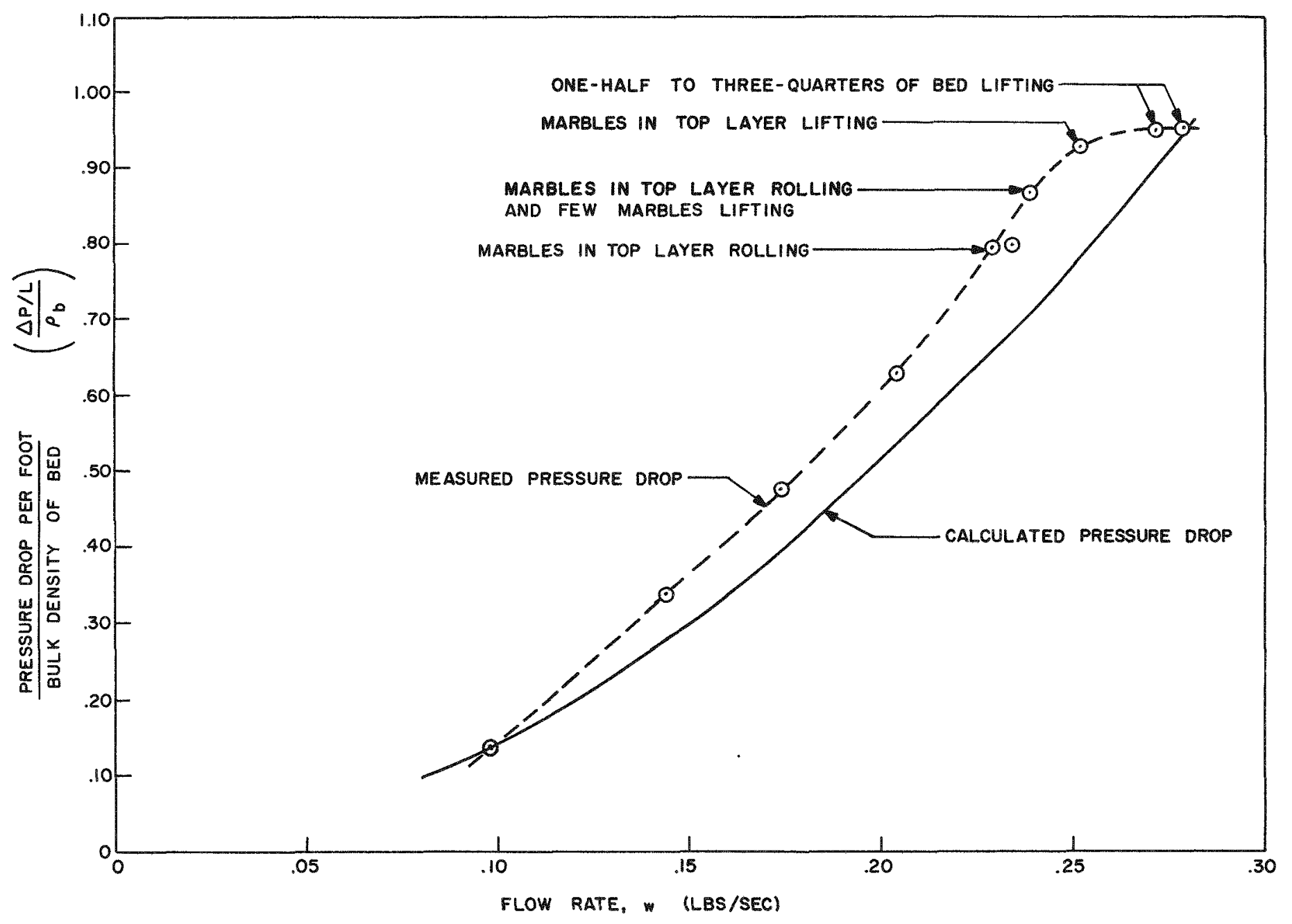

Figure 5. Pressure Drop versus Flow Rate for the Pebble Bed 
Bloom gives the following equation for calculating pressure drop through pebble beds: * *

$$
\frac{\mathrm{dP}}{\mathrm{dx}}=2.4\left(\mathrm{R}_{\mathrm{e}}\right)^{-0.1}\left(\frac{1-\mathrm{e}}{\mathrm{e}}\right) \frac{\mathrm{w}^{2}}{\rho_{1} \mathrm{gda}^{2}}
$$

This equation has been used to calculate a pressure drop based on Reynolds number and air density at the bed inlet, and the results have been plotted in Figure 5 for comparison with the measured values. This equation gives values approximately 15 to 18 percent lower than the measured values over most of the range investigated. Bloom states, however, that this equation has a probable accuracy of only 35 percent. The measured values of pressure drop correlate very well with other experimental pressure drop data (Figure 6), presented by Carman, showing a scatter of \pm 12 percent in the dimensionless pressure drop parameter for the Reynolds number range covered.

Movies were made of the pebbles lifting. Figure 7 comprises prints of every fifth frame of these movies, covering 1 cycle of pebble motion. The movies were made at 64 frames per second; therefore, successive figures represent a time interval of 0.078 second.

Since the air temperature in this test did not vary along the bed, the above results would be representative of the behavior of that section of a heater pebble bed where the air has attained the maximum temperature. The spinning motion in the top layer of marbles becomes apparent at a pressure drop equivalent to approximately 80 percent of the bed bulk density, and lifting of the top-layer marbles occurs at a pressure drop equivalent to approximately 85 percent of bed bulk density.

\section{Transient Pressure Drop}

An attempt was also made to determine the reaction of the pebble bed to the rapid pressure buildup experienced in starting a blowdown wind tunnel where the heater is not prepressurized. These conditions were simulated by presetting the globe valve to restrict the maximum flow rate. By opening the one-quarter-turn plug valve as rapidly as possible, 'starts' were obtained with pressure buildup of the order of 3 psi per second at the bed inlet. 'Starts' were made, recording total pressure at the bed inlet during this transient, and were repeated, measuring pressure drop across the bed. The pressure drop trace reacts similarly to the total pressure trace. The pebbles did not lift until the peak pressure drop during this transient attained a value approximately the same as that at which lifting occurred at steady-state conditions. However, since the rate of pressure increase in a pebble heater would have to be much greater than was obtainable in this test, these results are not representative of actual conditions. 


\section{Conclusions and Recommendations}

1. Porosity of cylindrical pebble beds at diameter ratios normally occurring in heater design varies from 35 to 40 percent.

2. This experiment indicated that the pressure drop calculated by Equation 3 is 20 percent lower than the measured pressure drop.

3. The top pebbles start spinning at a pressure drop equivalent to 80 percent of bed bulk density, and lifting occurs at a pressure drop equivalent to 85 percent of bed bulk density.

4. A maximum design value of 80 percent of bed bulk density should be used for allowable pressure drop. 


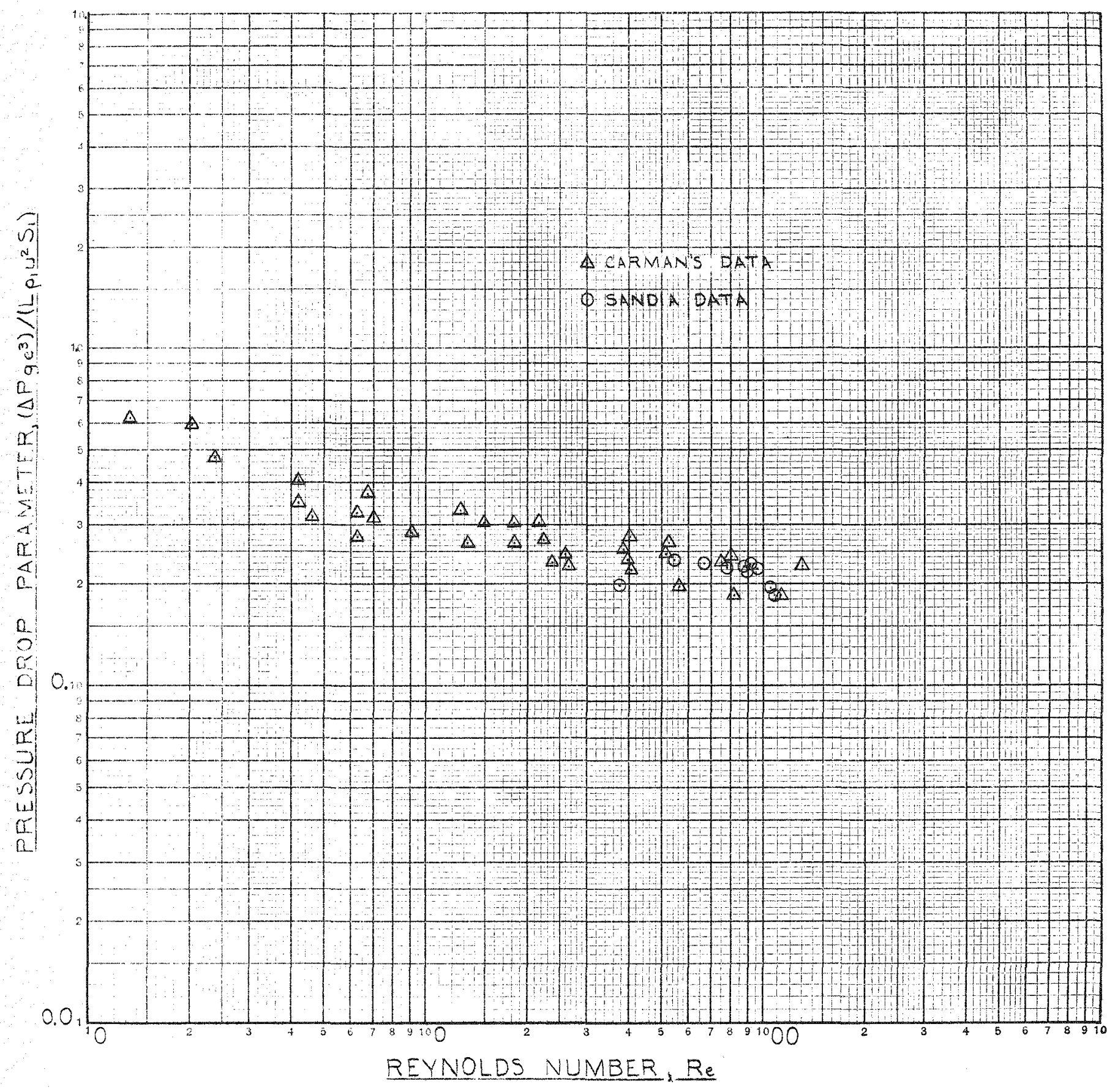

Figure 6. Pressure-Drop Parameter versus Reynolds Number for the Pebble Bed 

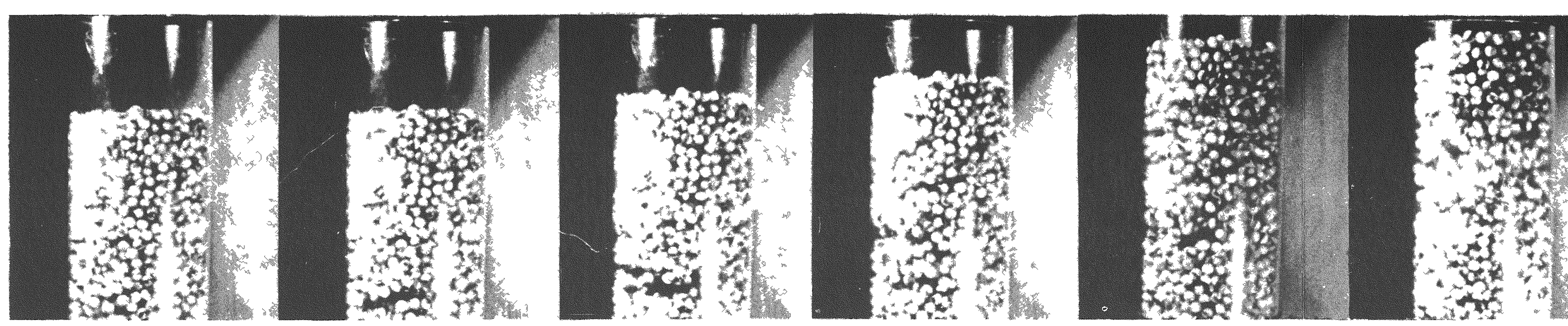

(a) Start of cycle, pebbles at Start of cycle,
rest, $t=0$ sec (b) Upper portion of bed lifting as a unit, $t=0.078$ sec (c) Upper portion of bed con-
tinuing upward, $t-0.156$

(d) Lower pebbles of lifted column falling back while upper pebbles continue to rise (e) More pebbles falling back while topmost pebbles con (f) More pebbles falling back While topmost pebbles con-
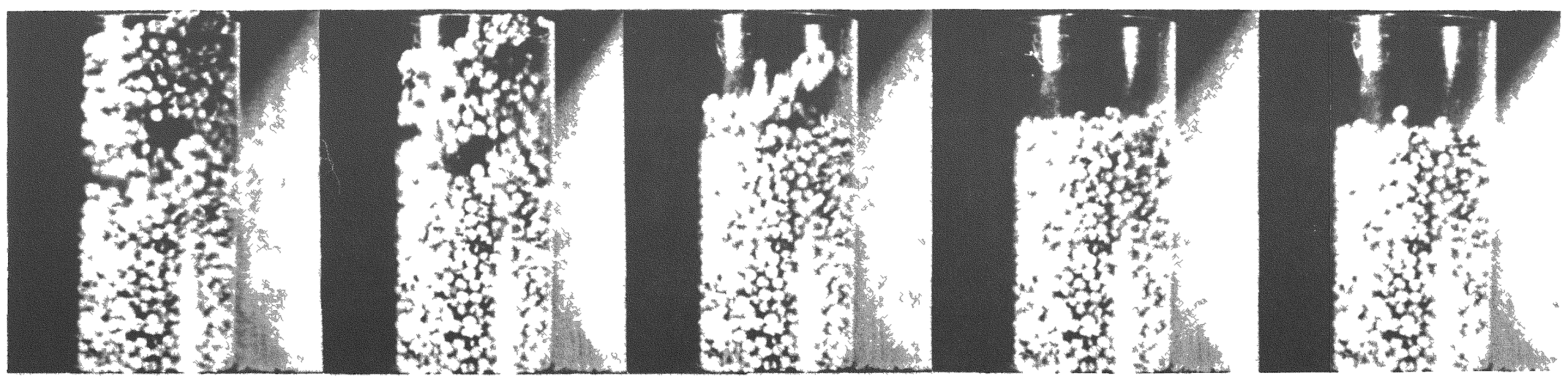

(g) Topmost pebbles attain
maximum displacement

(h) All pebbles starting to
fall back, $t=0.546 \mathrm{sec}$

(1) All pebbles falling back,

(j) All pebbles falling back, $\mathrm{t}=0.468 \mathrm{sec}$

Figure 7 Reproductions of Selected Frames of Motion-Picture F11m of Pebbles in Motio

(k) End of cycle, pebbles returning to rest 
$$
\text { . }
$$ 


\section{DISTRIBUTION}

Mrs. Jean O'Leary, DMA

K. F. Hertford, ALO

C. C. Campbell, SAO

N. E. Bradbury, LASL

NASA, Ames Laboratory

NASA, Cleveland Laboratory

NASA, Langley Laboratory

Aerodynamic Test Laboratory, Attn: J. H. Carrington

Boeing Airplane Co., Attn: J. H. Russell

Ballistics Research Laboratory, Attn: H. E. Maloy

Cornell Aeronautical Laboratory, Attn: K. D. Bird

Convair, Attn: W. T. MacCarthy

Chance Vought Aircraft Corp., Attn: R. C. McWherter

Southern California Cooperative Wind Tunnel, Attn: P. F. Keller

Douglas Aircraft Company, El Segundo, Attn: R. W. Bratt

David Taylor Model Basin, Attn: S. De Los Santos

Grumman Aircraft, Attn: Wm. Gander

Gas Dynamics Facility, AEDC, Attn: R. Jackson

Gas Dynamics Laboratory, Princeton University, Attn: Seymour M. Bogdonoff

Jet Propulsion Laboratory, Attn: Wm. Howard

Lockheed Aircraft Corp., Attn: Paul Theriault

Marquardt Aircraft Company, Attn: Wm. Braithwaite

McDonnell Aircraft Company, Attn: Robert E. Rohtert

Norman Engineering Company, Los Angeles, Attn: W. D. Lanier

North American Aviation, Inc., Attn: W. Daniels, Jr.

National Aeronautical Establishment, Ottawa, Attn: K. Orlik-Rlkckemann

Naval Ordnance Laboratory, Attn: Fred DeMerritte

Navy Supersonic Laboratory, Attn: D. H. Ross

Ohio State University, Attn: Dr. J. D. Lee

Polytechnic Institute of Brooklyn, Attn: Dr. M. Visich, Jr.

Redstone Arsenal, Attn: E. B. May

Republic Aviation Corporation, Attn: C. Cravero

Rosemount Aeronautical Laboratories, Attn: S. T. Vick

United Aircraft Corporation, Attn: I. Twomey

University of Michigan, Attn: Dr. H. P. Liepman

Wright Aeronautical Development Center, Attn: P. P. Antonatos

AFSWC (21)

ASTIA, Arlington 12, Va., Attn: TIPDR (10)

TISE (325)

OTS (75)

P. W. Rowe, 1231

G. A. Fowler, 5000

C. F. Quate, 5100

G. E. Hansche, 5130

A. Y. Pope, 5140

R. S. Claassen, 5150

H. R. Vaughn, 5141

R. C. Maydew, 5142

K. F. Crowder, 5143

W. H. Curry, 5144

D. E. Randall, 5142

J. McMinn, 8221

M. Randle, 3421-2

R. K. Smeltzer, 3421-3

W. F. Carstens, 3423

W. K. Cox, 3466-1 (13) 